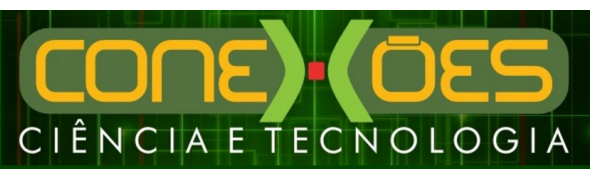

\title{
O DISCURSO POLÍTICO DE MICHEL TEMER: UMA ANÁLISE À LUZ DA GSF E DA ACD
}

\author{
Francisco Leones Alves da Silva, Vilmar Ferreira de Souza Correio \\ Instituto Federal de Educação, Ciência e Tecnologia do Ceará (IFCE), campus de Crateús \\ <leonesbond@gmail.com>, <vilmardesouza@ifce.edu.br>
}

DOI: 10.21439/conexoes.v12i2.1583

\begin{abstract}
Resumo. O Brasil tem vivido recentemente tempos bastante conturbados em sua história política. Pela segunda vez, um presidente é deposto acusado de cometer crime contra a Constituição. Nesse contexto, este trabalho investiga como estas relações se fazem presentes na materialidade do discurso do então presidente Michel Temer. Entendendo o discurso como constitutivo das práticas sociais e, portanto, ideológico, analisar o primeiro pronunciamento de Temer como presidente se faz necessário para se compreender o seu papel no atual contexto histórico-político brasileiro. Este trabalho objetiva responder, basicamente, à seguinte pergunta de pesquisa: Como o atual presidente Michel Temer representa, linguisticamente, a si mesmo e ao seu governo, em seu primeiro pronunciamento à nação como Presidente da República? Para tanto, nos utilizamos a Gramática Sistêmico-Funcional, em particular, a metafunção ideacional, com o seu sistema de transitividade, como instrumento de descrição linguística, e a discussão dos achados foi feita a partir da Análise Crítica do Discurso (ACD), com foco em sua terceira dimensão, em específico, na noção de ideologia na análise de discurso político. Os resultados apontam para a proeminência de processos materiais, através dos quais Temer representa seu governo como dinâmico e progressista ao passo que representa o governo anterior como retrógrado e inoperante.
\end{abstract}

Palavras-chaves: Discurso político. Gramática Sistêmico-Funcional. Sistema de Transitividade. Análise Crítica de Discurso. Michel Temer.

MICHEL TEMER'S POLITICAL SPEECH: AN ANALYSIS OF THE GSF AND ACD

\begin{abstract}
Brazil has recently experienced rather troubled times in its political history. For the second time since the end of the military dictatorship, a president is impeached from office charged with committing a crime against the Constitution. Within this context, this work investigates how these relations are present in the materiality of the speech of the then president Michel Temer. Based on the assumption that discourse is constitutive of social practices and it is therefore ideological, analyzing his Inaugural Address as president becomes extremely necessary to understand its role in the current Brazilian political arena. The present paper aims to answer, basically, the following: a) How does Mr Temer linguistically represent himself and his government in his Inaugural Address as President of Brazil? To answer this, we focused on the Systemic-Functional Grammar, in particular, on the ideational metafunction as realized by the system of transitivity, as for the linguistic description, and the discussion of the findings was carried out based on Critical Discourse Analysis (CDA), focusing on his third dimension, in particular, on the notion of ideology in political discourse analysis. The results point to the prominence of material processes through which Temer represents his government as dynamic and progressive while representing the previous government as static and outdated.
\end{abstract}

Keywords: Political speech. Systemic-Functional Grammar. Transitivity System. Critical Discourse Analysis. Michel Temer. 


\section{INTRODUÇÃO}

O Brasil tem vivido tempos bastante conturbados em sua história política. Pela segunda vez, desde o fim da ditadura militar, um presidente é deposto de seu cargo acusado de cometer crime contra a constituição. O impeachment, estado de excepcionalidade de um país, traz sempre consigo uma carga de notórias mudanças sociais e nas relações de poder estabelecidas. Pensando nestas mudanças em curso é que este trabalho visa uma investigação sob como estas relações se fazem presentes na materialidade do discurso do então presidente da república Michel Temer.

Partindo do pressuposto de que o discurso é constitutivo das práticas sociais e que são, em sua essência, também ideológicas, e de que estas estão sempre em contínuo processo de construção e reconstrução, analisar o primeiro pronunciamento de Michel Temer como presidente, neste cenário de intensa disputa ideológica por poder, se faz extremamente necessário para se compreender o seu papel no atual contexto históricopolítico brasileiro. Entendendo o discurso como uma prática social capaz de representar o mundo significativamente (FAIRCLOUGH, 2001, p. 91), este trabalho objetiva responder, basicamente, a um questionamento: 1) Como o atual presidente Michel Temer representa a si e ao outro linguisticamente em seu primeiro pronunciamento à nação como presidente da república?

Para tal empreendimento, utilizamos a Gramática Sistêmico-Funcional (HALLIDAY; MATTHIESSEN, 2014), em particular, a metafunção ideacional, com o seu sistema de transitividade, como instrumento de descrição linguística, e a discussão dos achados foi feita a partir da Análise Crítica do Discurso (ACD), com foco em sua terceira dimensão (FAIRCLOUGH, 2001), em específico, na noção de ideologia na análise de discurso político, conforme expandida em Souza (2015).

Este trabalho encontra-se organizado da seguinte maneira: em primeiro lugar, apresentamos a discussão sobre a fundamentação teórica que embasa este trabalho, a saber, o contexto de cultura com o seu conceito de ideologia e a Gramática Sistêmico-Funcional, com foco na metafunção ideacional, que é realizada pelo sistema de transitividade no nível da léxico-gramática, da qual nos utilizamos como ferramenta de descrição textual. Em seguida, apresentamos os dados linguísticos obtidos a partir da descrição linguística usando o sistema de transitividade do texto fundador do presidente Michel Temer.

Por fim, discutimos as implicações desses dados sobre as relações de poder entre ele e o grande público e entre ele e seus opositores, utilizando o conceito multiestratal de ideologia de Souza (2015), a partir da terceira dimensão do arcabouço analítico de Fairclough (2001).

\section{FUNDAMENTAÇÃO TEÓRICA}

\subsection{Contexto de cultura e discurso político}

O processo de impeachment imputado à Dilma Rousseff não tem sido unanimemente aceito como legítimo por parte da população brasileira, tendo, inclusive, defensores da ex-presidente (incluindo sua defesa e ela própria), que denunciam uma suposta formação de coalizão que seria responsável por arquitetar uma manobra para destituí-la do cargo de forma inconstitucional, ou seja, seus defensores sustentam que o acontecido com Dilma Rousseff se configurou em um 'golpe' de estado (SOUZA, 2016), por exemplo.

Isto criou uma atmosfera de intensa polarização política no país, com defensores do antigo governo não reconhecendo a legitimidade do atual, de um lado, e defensores do governo em exercício, do outro, sustentando a acusação contra a ex-presidente de ter cometido os crimes pelos quais ela foi julgada e condenada. Este cenário acima descrito tem se mostrado um verdadeiro campo de batalha ideológica em que o discurso assume um papel fundamental.

Esta luta linguística e ideológica que o presidente busca travar com seus opositores faz ressoar o conceito de ideologias que, para Fairclough(2001, p. 117), compreende

\footnotetext{
Significações/construções da realidade (o mundo físico, as relações sociais, as identidades sociais) que são construídas em várias dimensões das formas/sentidos das práticas discursivas e que contribuem para a produção, a reprodução ou a transformação das relações de dominação.
}

Além de alinhar-se à noção transformadora de ideologia presente em Fairclough (2001), esta análise busca também situar-se no estrato político do conceito multiestratal proposto por Souza (2015), que entende ideologia como simultaneamente antropológica, política, social, religiosa, histórica e semiótico-discursiva, como representada na figura 1

Cabe ressaltar que as relações de poder aqui discutidas e analisadas seguem o princípio político alinhandose mais a esse estrato do conceito proposto, mas que não necessariamente restringe-se exclusivamente a este. Sobre a relação entre os estratos da ideologia entendida como "ferramenta de análise linguístico-discursiva" (SOUZA, 2015, p. 422), o autor esclarece que "a relação, pois, entre os vários níveis representados acima, 


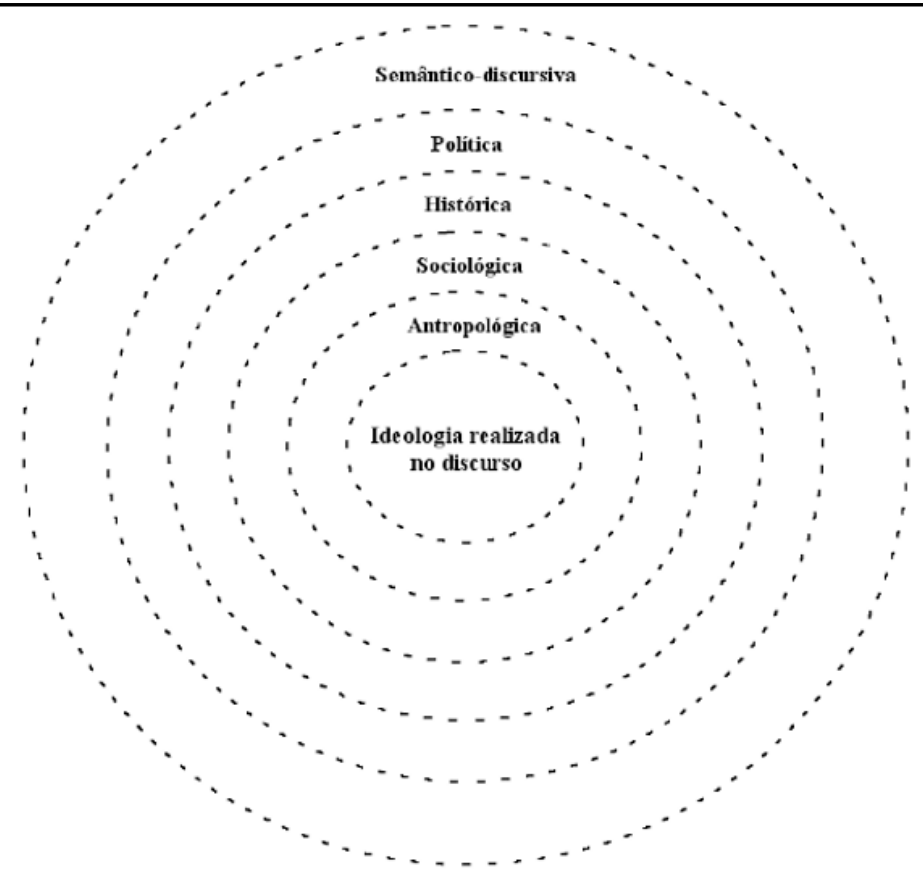

Figura 1: conceito multiestratal de ideologia Fonte: Adaptado de Souza $\sqrt{2015}$ p. 427)

só pode se caracterizar pelo princípio da simultaneidade" (Ibid.. p. 427). Além da natureza multiestratal do conceito defendida aqui, o referido autor sugere que o conceito de ideologia constitua o contexto de cultura necessário para este trabalho.

No presente trabalho compreendemos que o conceito de ideologia delimitado aqui nos ajuda a visualizar um espaço analítico no qual se inscreve o discurso político do então presidente em exercício. Além do mais, o referido trabalho nos possibilita clarear a própria definição de discurso político que, para Souza (2015, p. 430) seguindo Chilton (2004), ele constitui "uma luta por poder, entre aqueles que o detêm e lutam para mantê-lo e aqueles que procuram resistir a esse poder".

Entendendo o discurso político do presidente Temer como uma instância da realização linguística dessa nova ideologia instalada no país, procuramos mostrar como ele constrói, linguisticamente, essa nova configuração político-ideológica do seu governo.

\subsection{Gramática Sistêmico-funcional e o sistema de transitividade}

Desenvolvida a partir dos estudos de Michael Halliday, desde o início da década de 60, a Gramática Sistêmico-funcional (GSF, doravante) aborda a língua como um complexo de estratos intra e extralinguísti- cos, organizados hierárquica e simultaneamente para a construção de significados.

Para a GSF, são dois os contextos que importam no processo de construção de significados: o contexto de cultura e o contexto de situação. O primeiro se refere, de acordo com Halliday, às crenças e valores de uma determinada comunidade, enquanto o segundo diz respeito aos aspectos mais imediatos do contexto e inclui as variáveis campo, relações e modo. Esses dois estratos contextuais dialogam com o estrato da semântica, formado pelas três metafunções advogadas por Halliady, a saber, a ideacional, a interpessoal e a textual. Essas metafunções, por sua vez, são realizadas, no estrato da lexicogramática, pelos sistemas de transitividade, modo e modalidade e tema, respectivamente. Para os limites deste trabalho, utilizamos apenas a metafunção ideacional, em sua dimensão experiencial, conforme realizada pelo sistema de transitividade.

Como todos os postulados da GSF, o sistema de transitividade é composto por categorias funcionais que operam dentro de um determinado contexto e é instanciado a partir da variável Campo do contexto de situação (FUZER; CABRAL, 2014).

Uma das funções da língua é a de representar o mundo e o responsável pela realização dessas representações no plano linguístico é o sistema de transitividade, 
segundo a perspectiva funcional. Ele inclui o processo, os participantes e as circunstâncias, conforme Figura 2 abaixo:

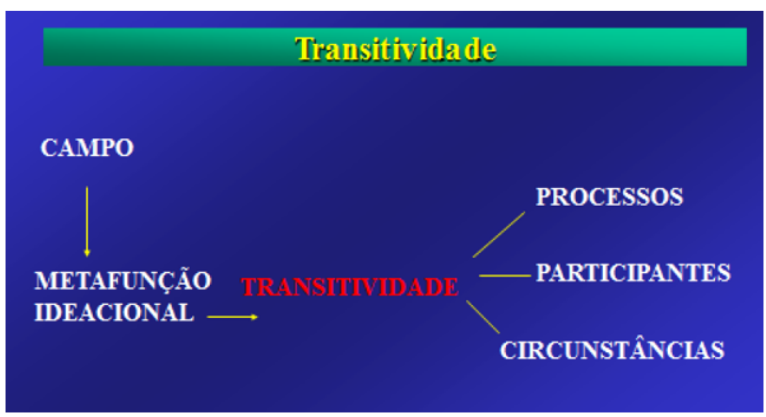

Figura 2: Sistema de Transitividade Fonte: CABRAL, 2015 p.14)

A combinação dessas categorias gera uma figura que representa um bloco de significação dentro de um determinado contexto comunicativo. Sobre esta relação, Fuzer e Cabral (2014, p. 41) nos mostram que:

Figuras são constituídas de um processo e participantes (quem faz o quê), e eventualmente, de circunstâncias associadas ao processo (onde, quando, como, por que etc.). As figuras são diferenciadas conforme tipos gerais de classificação dos processos: figuras de fazer e acontecer, de sentir, de dizer, de ser e ter, de existir e de comportar-

Estas figuras constituem o âmago das nossas representações linguísticas do mundo. São elas, portanto, o sumo da expressão de nossas experiências. Cada forma linguística de representar o mundo encontra-se atrelada a uma categoria específica de processo. Isto significa dizer que, para cada uso que fazemos da língua enquanto representação experiencial, estamos acionando determinado tipo de processo, categorizados por Halliday e Matthiessen (2004) como materiais, relacionais, mentais, existenciais, verbais e comportamentais.

Na Figura acima, podemos notar que três processos se encontram em destaque, isto porque Halliday (1994 1985 apud LIMA LOPES, 2001) entende que estes são os processos principais, sendo as demais intersecções entre estas categorias conforme ilustrado.

Dadas as limitações de tempo e espaço, trataremos, a seguir e mais detalhadamente, do processo que teve mais relevância nesta pesquisa 1 : o processo material. Os processos materiais são os que estão relacionados com ações concretas no mundo físico, podendo estas

\footnotetext{
${ }^{1}$ Para os detalhamentos dos demais processos ver Halliday e Matthiessen $(2004 ; 2014)$
}

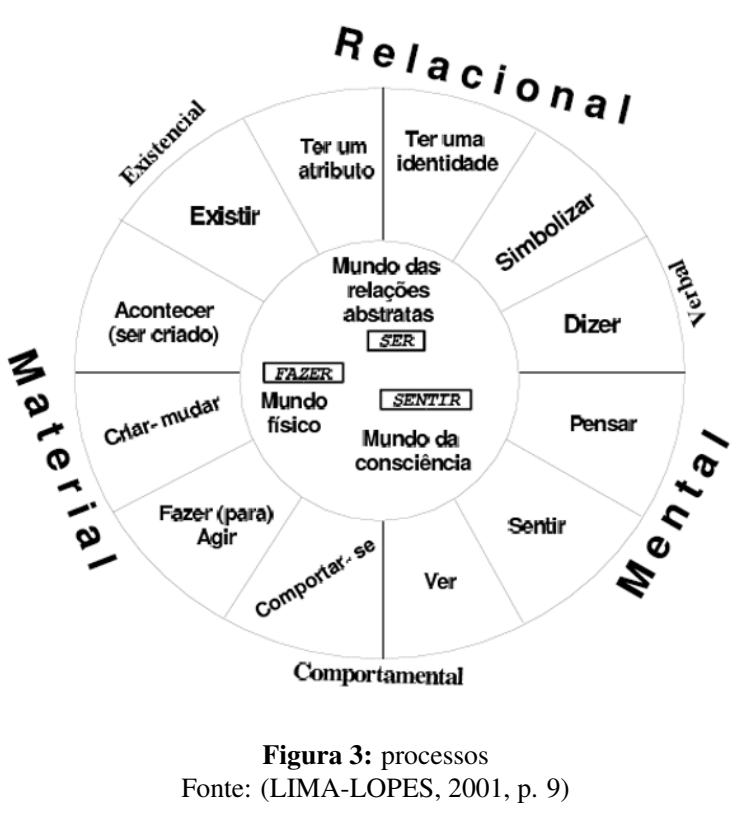

serem de criação ou de transformação. Nas palavras de Gouveia (2009, p. 31):

\begin{abstract}
Os processos materiais são, prototipicamente, representações de acções concretas, físicas, isto é, dão conta de mudanças no mundo material que podem ser percepcionadas, comprovadas, vistas. Porém, as actividades concretas observadas no mundo material tornaram-se referentes, modelos, para a construção da nossa experiência de mudança relativamente a fenómenos abstractos. Quer isto dizer que algumas representações de processos materiais são representações de processos de fazer de teor abstracto, como, por exemplo, na oração "A inflação subiu no primeiro trimestre deste ano".
\end{abstract}

Estes processos possuem cinco participantes distintos que, a depender do campo semântico que criam, acionam diferentes tipos de participantes, como mostrados na Tabela 1 .

Uma vez discutida a base teórica deste estudo, a seguir, apresentamos o percurso metodológico seguido.

\section{PERCURSO METODOLÓGICO:}

\subsection{Seleção do corpus:}

Nesta pesquisa analisamos o primeiro pronunciamento do atual presidente da República em cadeia nacional de rádio e televisão. Consideramos aqui "o primeiro pronunciamento como presidente" o primeiro que foi feito após sua efetivação no cargo, ou seja, após o processo de impeachment que o nomeou, por sucessão constitucional, como representante maior da República brasileira. 


\begin{tabular}{|c|l|}
\hline Participante & \multicolumn{1}{c|}{ Descrição } \\
\hline O Ator & aquele que pratica a ação descrita no processo \\
\hline A Meta: & é o participante a quem a ação se dirige \\
\hline O Escopo: & $\begin{array}{l}\text { é um participante que tem uma certa independência em relação } \\
\text { ao processo }\end{array}$ \\
\hline O Recebedor: & $\begin{array}{l}\text { está presente em orações que representam a transferência de } \\
\text { posse de bens ou informações, como o próprio nome o sugere } \\
\text { ele é o recebedor desses. }\end{array}$ \\
\hline O Cliente: & $\begin{array}{l}\text { muito semelhante ao recebedor, também cumpre a função de } \\
\text { ser beneficiado por alguma meta, com o agravante de que, no } \\
\text { ção deste participante, os processos têm a conotação de cria- } \\
\text { participante representa a entidade para quem alguma coisa é é } \\
\text { feita, criada ou transformada". }\end{array}$ \\
\hline
\end{tabular}

Retiramos o texto para análise do site oficial do palácio do planalto: <www2.planalto.gov.br $>$ encontrado na aba "Discursos" sob o título de "Pronunciamento do Senhor Presidente da República, Michel Temer, em cadeia de rádio e televisão" publicado no dia 31/08/2016 2. A escolha por este discurso se justifica pelo fato de ser através dele que o então presidente procura estabelecer os parâmetros de seu governo, em oposição ao governo recentemente deposto.

\subsection{Procedimentos de análise e categorização dos dados:}

Em um primeiro momento, separamos todo o discurso em complexos oracionais e estes em orações, que foram devidamente enumerados utilizando um critério de pontuação para definir a extensão do complexo analisado. Em seguida, analisamos cada oração em relação à sua realização lexicogramatical, identificando o processo, seus participantes e circunstâncias, seguindo Souza et al. (2011), conforme a Tabela 2.

Feito isso, desenhamos o mapa da transitividade que nos mostrou serem os processos materiais os mais importantes para responder à pergunta proposta neste trabalho, a saber, como o presidente Michel Temer representa a si mesmo e seu governo em seu primeiro texto dirigido a nação brasileira como presidente.

\section{RESULTADOS E DISCUSSÃO}

Uma vez feita a análise de transitividade em todo o texto, o resultado que obtivemos encontra-se na Tabela 3

${ }^{2}<$ http://www2.planalto.gov.br/acompanhe-planalto/discursos/ discursos-do-presidente-da-republica/pronunciamento-do-senhordo-presidente-da-republica-michel-temer-em-cadeia-de-radio-etelevisao>
Como podemos observar no quadro acima, os processos são, em sua grande maioria (48,2\%), materiais, motivo pelo qual os escolhemos para a presente análise. Isso nos diz que há uma forte tendência, dentro do discurso político de Michel Temer, de representar 'ações concretas' que são a característica básica deste tipo de processo

Ao investigarmos essa proeminência dos processos materiais, percebemos que em mais da metade das ocorrências o participante Ator (aquele que realiza a ação), é a primeira pessoa do discurso (eu / nós) ${ }^{3}$, ou seja, Michel Temer está presente diretamente em cerca de $51,8 \%$ (14 ocorrências) das ações representadas pelos processos materiais. Das restantes, em 11,1\% (3 ocorrências) Temer se inclui de forma indireta, não sendo o Ator do enunciado mas estando este ligado diretamente a ele por possessão, nas formas: 'Nosso objetivo', 'Nossa missão' e 'Meu único interesse'.

As demais ocorrência são ações realizadas por entidades variadas, sendo elas: A incerteza, Ela (elipse para 'sua família' presente na oração anterior), $O$ governo, Um sistema, Indicadores da economia, O estado brasileiro (em elipse), O Minha Casa Minha Vida, Os jogos olímpicos, Um país e Deus. Estas representam o restante, cerca de $37 \%$ do total de enunciados materiais, mas em nenhum momento repetem-se como participante Ator dos enunciados materiais, diferentemente das demais ocorrências em que o presidente inclui-se como praticante da ação descrita no processo.

Dos 14 enunciados materiais em que o presidente inclui-se diretamente como agente da ação, 13 estão no plural. Ou seja, em quase todos quem pratica a ação

\footnotetext{
${ }^{3}$ Uma observação interessante que pode vir a ser fruto de pesquisas futuras é a que o recurso da elipse é muito utilizado neste discurso. Pelos recortes necessários que fizemos e os objetivos desta pesquisa, não pudemos investigar esta questão a fundo, porém fica aqui como sugestão de pesquisa.
} 
Tabela 2: modelo de oração analisada.

\begin{tabular}{|c|c|c|c|}
\hline \multirow{2}{*}{15} & {$[$ Nós] } & Reduzimos & o número de ministérios. \\
\cline { 2 - 4 } & Part. Ator & Proc. Material & Part. Meta \\
\hline
\end{tabular}

Tabela 3: Tabulação dos dados linguísticos

\begin{tabular}{|c|c|c|}
\hline PROCESSO & QUANTIDADE DE OCORRÊNCIAS & $\boldsymbol{\%}$ \\
\hline Material & 27 & 48,2 \\
\hline Relacional & 18 & 32,1 \\
\hline Mental & 5 & 8,9 \\
\hline Verbal & 3 & 5,3 \\
\hline Comportamental & 3 & 5,3 \\
\hline Existencial & 0 & 0 \\
\hline
\end{tabular}

é o Ator 'Nós'. Dado o conteúdo semântico das ações é possível inferir que este 'Nós' refere-se ao governo federal, tendo como principal representante o próprio Temer, exemplo disso são as orações 15 e 16.

Aqui os processos descritos, claramente, só podem ser realizados pelo governo. Podemos inferir então que Michel Temer se inclui como governo. Entretanto, há situações em que ele, através de suas escolhas linguísticas, exclui-se dessa categoria. É o caso do enunciado 19 em que 'o governo' aparece lexicalizado como agente da ação, fugindo do padrão inclusivo até então observado:

Notemos que ao escolher a construção "o governo não terá como pagar" em detrimento à "Nós não teremos como pagar" ou "Não teremos como pagar" simplesmente, Temer exclui-se do processo e consequentemente da categoria 'governo', estando essa apresentada em terceira pessoa, diferentemente do que ocorre nos enunciados 15 e 16 .

De modo semelhante, este processo de exclusão se dá no enunciado 17 em que a referida categoria é lexicalizada como uma Meta.

Aqui o Ator é precisamente o próprio governo, isto significa que, mais uma vez, Michel Temer poderia optar por construções alternativas que evitassem a aparente redundância semântica como "Estamos diminuindo nossos gastos" mas não o fez.

Fica claro com isto que o presidente representa a si como pertencente a classe 'governo' através da utilização de verbos flexionados na primeira pessoa do discurso quando o teor das ações parece possuir uma carga semântica positiva à maioria da população brasileira, como nas orações 32 e 33 em que são descritas as ações governamentais de 'ampliar os programas sociais' e 'aumentar o valor do bolsa família' respectivamente. Assim como fica clara sua manifesta exclusão linguística de enunciados em que relacionam-se a esta categoria uma carga semântica negativa como 'Não ter como pagar os aposentados' ou 'Ter gastos a serem cortados', enunciados 19 e 17 respectivamente.

Como já mostramos aqui, a análise linguística que fizemos aponta para uma prevalência do 'governo' como maior ator das ações materiais descritas pelos processos. É nestas orações onde se encontram mais indícios da ideologia de direita a que se alinha o novo presidente. Exemplo disso são as orações 25 e 26 em que Michel Temer demonstra sua visão de como resolver o problema do desemprego através do fortalecimento da iniciativa privada no país, o que historicamente associase mais a um pensamento da direita política, que entende que o mercado deve regular a economia com a menor interferência possível do Estado.

Este pensamento opõe-se ao dos três últimos governos que o antecederam, que entendiam ser o fortalecimento dos programas sociais um aliado importante no crescimento econômico do país. Isto vem a se alinhar mais a um pensamento de esquerda, que entende que há a necessidade de termos uma distribuição de renda mais justa para que haja uma diminuição das diferenças sociais.

Temer entendendo que seu governo traz uma drástica modificação na forma de se governar, busca estratégias linguísticas que visem infiltrar elementos do pensamento político ao qual se alinha, dentro de medidas que se mostram necessárias para retomada do crescimento do país.

Embora essa polaridade direita/esquerda precise ser questionada e não o será aqui por limitação de espaço, o discurso do novo presidente se alinha à uma ideologia que prima pelas ações que valorizam os setores mais conservadores da sociedade brasileira, em detrimento das camadas mais carentes da população.

Ao construir o seu espaço semântico como um espaço de homem de ação, Temer quer dizer que seus antecessores perderam a capacidade de agir sobre os problemas nacionais e, portanto, tiveram que ser destituí- 


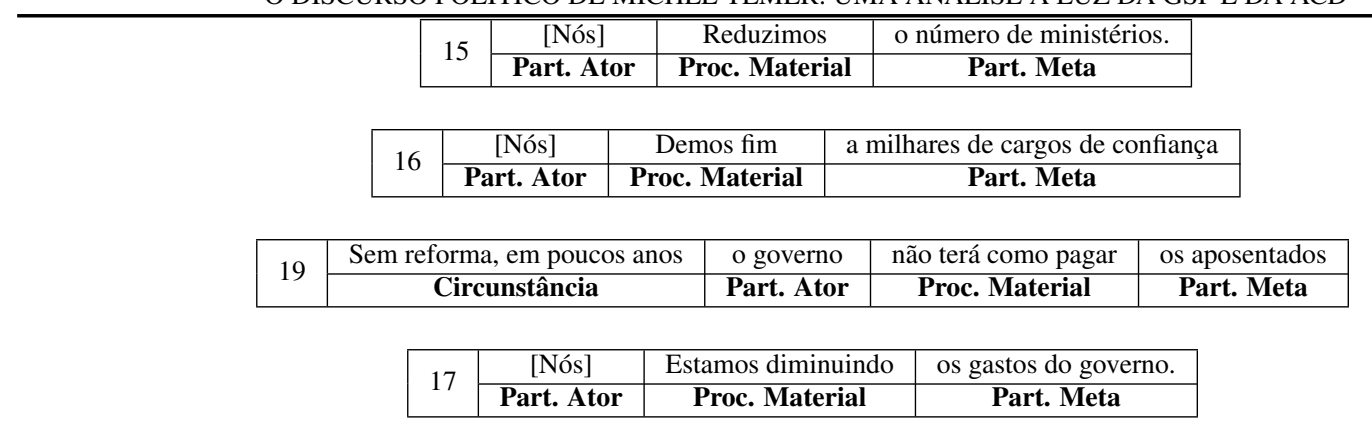

dos via o impeachment da presidente Dilma Rousseff. Embora amplamente aceito por vários setores da sociedade brasileira, o impeachment tem encontrado muita resistência em vários outros setores, a ponto de Souza (2016) defender que o que aconteceu no Brasil foi um golpe de estado de uma elite política insatisfeita com os destinos do país com uma orientação mais popular orientada para a esquerda. Ainda segundo o mesmo autor, a arma usada para destituir a ex-presidente Dilma do cargo, a corrupção, tem se mostrado completamente insustentável, uma vez que os escândalos de corrupção só têm aumentado no governo Temer.

Noutras palavras, o conceito de ideologia conforme abordado aqui com o seu conseguinte conceito de discurso político, ajudou a compreender como a configuração ideológica que divide a política do país em dois blocos, esquerda e direita, se mostrou, linguisticamente, no primeiro discurso do presidente Michel Temer.

\section{CONSIDERAÇÕES FINAIS}

Neste trabalho procuramos responder à pergunta norteadora que consiste em averiguar de que maneiras o atual presidente Michel Temer representa, linguisticamente, a si mesmo e ao seu governo, em seu primeiro pronunciamento à nação como Presidente da República. A partir da análise da transitividade, ficou demonstrado que em sua grande maioria, o presidente escolhe os processos materiais, $48,2 \%$, para representar a si mesmo e o seu governo com uma alternativa de governo moderno e dinâmico fazendo um contraponto ao governo anterior. Esse achado, no nível da lexicogramática foi interpretado como sinalizando para a construção de um espaço político de direita, em contraposição ao governo anterior, compreendido como de esquerda. Essa figura ideológica foi construída a partir do olhar político do sociólogo Souza (2016) que considera um impeachment como um golpe de Estado.

Embora esse debate necessite de várias páginas de discussão, as limitações de espaço nos obrigaram a simplifica-la aqui. No entanto, ela abre caminhos para um debate rico em relação a essa dicotomia esquerda/direita no Brasil, juntamente com os discursos que circulam que ratificam, ou não, esse construto. Além dessa janela de expansão, também faltou a discussão a respeito do papel dos outros processos no discurso do presidente, o que poderá ser feito oportunamente. Expandindo ainda mais esse trabalho, fica a proposta de averiguar em estudos futuros os aspectos interpessoais na construção da identidade do presidente e das identidades de seus interlocutores.

Para além do exposto, a tarefa em lidar com um conceito tão abstrato e potencialmente perigoso como o de ideologia nos rendeu o lucro de localizar a discussão em um de seus estratos, o político, para em seguida, expandir a discussão para a dicotomia esquerda/direita como ao menos sinalizado como problemática neste texto. Essa discussão do aspecto ideológico deve por fim contribuir para a elucidação dos elementos ideológicos presentes em todo o texto, fato que, apesar de sua aparente obviedade, nos escapa facilmente, em nossas práticas sociais, o que nos faz ingenuamente pensar na opacidade dos discursos. Como nos mostra Fairclough (2001, p. 120):

\footnotetext{
Não se deve pressupor que as pessoas têm consciência das dimensões ideológica de sua própria prática. [...] Mesmo quando nossa prática pode ser interpretada como de resistência, contribuindo para a mudança ideológica, não estamos necessariamente conscientes dos detalhes de sua significação ideológica. [...]
}

\section{CONSIDERAÇÕES FINAIS}

Para longe de objetivarmos esgotar o potencial analítico que contém o discurso que aqui analisamos, buscamos elucidar algumas estratégias linguísticas potencialmente revestidas de ideologia afim de trazer uma pequena contribuição aos estudos que se ocupam desta mesma problemática. Longe de fechar esse tópico, a análise empreendida aqui apenas sinaliza a necessidade de mais investigação na área intitulada de Análise do 
O DISCURSO POLÍTICO DE MICHEL TEMER: UMA ANÁLISE À LUZ DA GSF E DA ACD

Discurso Político, como uma forma de descortinarmos as entrelinhas dos discursos que circulam em nossa sociedade e que estão prenhes de conteúdo ideológico contrário à construção de uma sociedade mais justa e mais igualitária.

\section{REFERÊNCIAS}

CABRAL, S. R. S. Transitividade e auto-representação em um debate político. Cadernos de Linguagem e Sociedade, v. 16, n. 1, p. 9-35, 2015.

FAIRCLOUGH, N. Discurso e mudança social. trad. Magalhães. Brasília: Editora Universidade de Brasília, 2001.

FUZER, C.; CABRAL, S. R. S. Introdução à gramática sistêmico-funcional em língua portuguesa. Mercado das Letras, Campinas, SP, 2014.

GOUVEIA, C. A. Texto e gramática: uma introdução à linguística sistêmico-funcional. Matraga-Revista do Programa de Pós-Graduação em Letras da UERJ, Rio de Janeiro, v. 16, n. 24, 2009.

HALLIDAY, M. A. K. An introduction to functional grammar. 2. ed. London: Routledge, 1994.

HALLIDAY, M. A. K.; MATTHIESSEN, C. An introduction to functional grammar. 4. ed. London: Routledge, 2014.

HALLIDAY, M. A. K.; MATTHIESSEN, C. M. An introduction to functional grammar. 3. ed. London: Hodder Education, 2004.

HASAN R. PART II. IN: HALLIDAY, M. A. K. H. H. Language, context, and text: Aspects of language in a social-semiotic perspective. Oxford University Press, Oxford, 1989.

LIMA, L. R. et al. Processos existenciais em reportagens de capa da revista Superinteressante. Metrado em Letras - Universidade Federal de Santa Maria, Santa Maria, 2013.

LIMA-LOPES, R.; VENTURA, C. S. M. A transitividade em Português. LAEL, Pontifícia Universidade Católica de São Paulo e AELSU, University of Liverpool, United Kingdom, 2008.

LIMA-LOPES, R. d. Estudos de transitividade em língua portuguesa: o perfil do gênero cartas de venda. Dissertação (Mestrado em Letras) — Pontifícia Universidade Católica de São Paulo, São Paulo, 2001.
PRONUNCIAMENTO DE MICHEL TEMER.

Pronunciamento do Senhor Presidente da

República, Michel Temer, em cadeia de rádio e televisão. Disponível em: <http://www2.planalto. gov.br/acompanhe-planalto/discursos/discursos-dopresidente-da-republica/pronunciamento-do-senhordo-presidente-da-republica-michel-temer-em-cadeiade-radio-e-televisao > Acesso em: 11/10/2016.

SOUZA, J. A radiografia do golpe: entenda como e por que você foi enganado. Rio de Janeiro: Leya, 2016.

SOUZA, V. F. d. et al. Power relations in Padre Cícero's epistolary political letters: an investigation in the light of systemic-functional grammar and critical discourse analysis. Tese (Doutorado em Letras) - Universidade Federal de Santa Catarina, Florianópolis, 2011.

SOUZA, V. F. de. O lugar do conceito de ideologia na análise do discurso político (ADP): uma proposta à luz da análise crítica do discurso (ACD). Letras, v. 25, n. 50, p. 421-432, jan./jun. 2015. 